\title{
MHD slip flow and heat transfer of Casson nanofluid over an exponentially stretching permeable sheet
}

\author{
Sudipta Ghosh and Swati Mukhopadhyay* \\ Department of Mathematics, The University of Burdwan, \\ Burdwan-713104, West Bengal, India \\ *Email: swati_bumath@yahoo.co.in
}

\begin{abstract}
The aim of the present paper is to discuss the boundary layer flow induced in a nanofluid due to a stretching permeable sheet in the presence of a magnetic field. Instead of no-slip boundary conditions, slips at the boundary have been considered. Casson fluid model was used to characterise the non-Newtonian fluid behaviour. The effects of Brownian motion and thermophoresis on heat and mass transfer were considered. Using similarity transformations, the governing partial differential equations were transformed into ordinary ones. The self-similar equations were then solved numerically using shooting technique with fourth order Runge-Kutta method. The solutions for velocity, temperature and concentration fields depended on the pertinent parameters. It was observed that the velocity decreased but the temperature and nanoparticle volume fraction increased with the increase of Casson fluid parameter. With the increase in velocity slip parameter as well as magnetic parameter, fluid velocity decreased. Due to increase in thermal slip, temperature decreased and with the increase in mass slip parameter, concentration also decreased. Temperature was found to increase but the nanoparticle volume fraction decreased due to the Brownian motion. On the other hand, temperature and nanoparticle volume fraction were both found to increase with the increase of thermophorosis parameter as well as with the increasing strength of magnetic parameter. Thus, velocity slip at the boundary and magnetic parameter acted as flow controlling parameters. It is believed that this type of investigation is very much helpful for the manufacturing of complex fluids and also for cleaning oil from surfaces.
\end{abstract}

Keywords: Nanofluid; Casson fluid; exponentially stretching sheet; slip boundary conditions; MHD; suction/blowing.

\section{INTRODUCTION}

An enormous amount of work has been done on the boundary layer flow and heat transfer past a stretching sheet [1]. The engineering applications of the stretching sheet problems include polymer sheet extrusion from a dye, drawing, tinning and annealing of copper wires, glass fibre and paper production, the cooling of a metallic plate in a cooling bath, aerodynamic extrusion of plastic sheets, heat treated materials travelling between a feed roll and a wind-up roll and so on [2]. An elegant analytical solution to the boundary layer equations for the problem of a steady two-dimensional flow due to a stretching surface in a quiescent incompressible fluid was first observed by Crane [3]. Gupta and Gupta [4] argued that realistically, stretching of plastic sheet may not necessarily be linear. The real processes can be modelled using different types of stretching velocities viz. (a) linear (b) 
power-law (c) exponential (d) hyperbolic which have a definite impact on the quality of the product obtained. Magyari and Keller [5] studied the boundary layer flow and heat transfer due to an exponentially stretching sheet. Many other researchers such as Elbashbeshy [6], Khan and Sanjayanand [7], and Partha et al. [8] have continued their work by considering exponentially stretching sheet. Mandal and Mukhopadhyay [9] analysed the heat transfer characteristics for flow past an exponentially stretching sheet embedded in a porous medium in the presence of surface heat flux. Recently, Hafidzuddin et al. [10] obtained the numerical solution for flow past an exponentially stretching/shrinking sheet. Mabood et al. [11] reported the effects of radiation on heat transfer over an exponentially stretching sheet. Nowadays, the enhancement of thermal conductivity is an extremely important topic among researchers. The term nanofluid was first used by Choi [12]. Masuda et al. [13] first observed the enhancement characteristics of thermal conductivity of nanofluid. By adding a small amount of nanoparticles (less than $1 \%$ by volume) in conventional heat transfer fluids, researchers showed the enhancement of thermal conductivity up to two times (approximately). Compared to the base fluids, thermal conductivity of nanofluid is very high [14-18] and so these are used in many energetic systems such as cooling of nuclear systems, radiators, natural convection in enclosures, drawing of copper wires, continuous stretching of plastic films, artificial fibres, hot rolling, wire drawing, glass fibre and metal extrusion and metal spinning, etc. Furthermore, due to their excellent wetting and spreading behaviour, nanofluids have important applications for cleaning oil from surfaces. Different models for nanofluid are available, among which Buongiorno's [19] model and the model proposed by Tiwari and Das [20] are very popular. Makinde and Aziz [21] analysed the effects of convective heating on boundary layer nanofluid flow due to a stretching sheet. Nanofluid flow over a permeable stretched surface near a stagnation point was discussed by Alseadi et al. [22]. Mustafa et al. [23] analysed the boundary layer flow of nanofluid over an exponentially stretching sheet with convective boundary conditions. The mixed convection peristaltic flow of magnetohydrodynamic (MHD) nanofluid in the presence of Brownian motion and thermophoresis was presented by Hayat et al. [24]. Zaimi et al. [25] used the two-phase model for nanofluid to investigate the effects of Brownian motion on thermophoresis for flow past a stretching/shrinking sheet. Usri et al. [26] discussed the forced convection flow using nanofluid and highlighted its applications in automotive cooling system. Stagnation point flow of nanofluid towards a stretching/shrinking sheet was investigated by Mansur et al. [27]. Naramgari and Sulochana [28] studied the combined effects of thermal radiation and chemical reaction on nanofluid flow towards a stretching/shrinking sheet.

The flow of non-Newtonian fluids with heat transfer has great importance in engineering applications such as the thermal design of industrial equipment dealing with polymeric liquids, molten plastics and food stuffs or slurries. In general, non-Newtonian models have nonlinear relationship between stress and rate of strain. Casson fluid is a shear thinning liquid treated as one kind of non-Newtonian fluid which exhibits yield stress. When less shear stress than the yield stress is applied, such fluid behaves like a solid i.e. no flow occurs and it moves if the applied shear stress is greater than the yield stress. Jelly, soup, honey, tomato sauce, concentrated fruit juices, blood etc. belong to the Casson fluid model. Boyd et al. [29] reported on the Casson fluid flow for the oscillatory blood flow. Mustafa et al. [30] investigated the unsteady flow of Casson fluid over a moving plate. Mukhopadhyay [31] discussed the combined effects of suction/blowing and thermal radiation on Casson fluid flow and heat transfer past an unsteady stretching surface. Nadeem et al. [32] obtained analytical solution for oblique flow of Casson 
nanofluid, while Haq et al. [33] studied the Casson nanofluid flow past a shrinking sheet. Mustafa and Khan [34] presented a model for Casson nanofluid flow towards a nonlinear stretching sheet in the presence of magnetic field. Recently, Umavathi and Mohite [35] investigated the heat transfer of nanofluid in porous media. Oyelakin et al. [36] investigated the unsteady flow of Casson nanofluid over a stretching surface and reported the effects of slip and convective parameter. Sulochana et al. [37] also studied the effects of convective parameter on three-dimensional Casson nanofluid flow in a porous medium. Rana et al. [38] analysed the homogeneous and heterogeneous chemical reactions on mixed convective flow of Casson fluid. Zaib et al. [39] obtained dual solutions for a mixed convection flow of Casson fluid past an exponentially shrinking sheet in the presence of viscous dissipation and suction. Vajravelu et al. [40] studied on the non-Newtonian fluid flow past a vertical stretching sheet considering the Ostwald-de Waele fluid model. In most of the papers mentioned above, no-slip boundary condition has been used. For cooling of electronic devices, micro heat exchanger systems, etc., microchannels which are at the front position of today's turbo machinery technologies are mostly being considered. But it is a well-known fact that for some coated surfaces and for micro-electro mechanical systems, the no-slip boundary condition is not valid. In such cases, slip boundary conditions are to be used. Fluids exhibiting slip at the boundary have significant technological applications. Turkyilmazoglu [41] obtained multiple solutions for MHD Viscoelastic fluid flow over a stretching sheet in the presence of slip. Sahoo and Poncet [42] discussed the second-grade fluid flow and heat transfer past an exponentially stretching sheet in the presence of slip. Uddin et al. [43] reported the combined effect of magnetic field and slip on stretching/shrinking nonlinear nanomaterial sheet in the presence of convective heating. Hayat et al. [44] investigated the effects of second order slip on nanofluid flow over a bidirectional stretching sheet. Recently, Ghosh et al. [45] obtained dual solutions for boundary layer slip flow over a nonlinear shrinking sheet with a more general shrinking velocity. Hayat et al. [46] investigated the effects of slip on unsteady MHD flow past an exponentially stretching sheet. Magnetic nanofluids have wider applications in the enhancement of magnetic resonance, aerodynamic sensors, nuclear plants, magnetic cell separation, drug delivery, cancer therapy, biological transport, and artificial kidneys [44-47]. Yet, very limited investigations dealing with magnetic nanofluids are available in open literature. Moreover, nanofluid exhibits slip behaviour. However, there is a huge gap in the area of research dealing with magnetic nanofluid flow in the presence of slips at the boundary. So, an attempt was made in this investigation to fill up this gap.

The motivation of the present paper is to study the boundary layer of nanofluid flow and heat transfer due to an exponentially stretching permeable sheet in the presence of a magnetic field and slips at the boundary. Velocity, thermal as well as mass slip conditions were considered. Casson fluid has been used as the base fluid. With the help of appropriate similarity transformations, the governing partial differential equations were reduced to a set of nonlinear ordinary differential equations. Using fourth order RungeKutta method with the help of shooting technique, these equations were then solved numerically. The effects of the various physical parameters on velocity, temperature, nanoparticle volume fraction, skin-friction, heat and mass flux coefficients have been reported. 


\section{METHODS AND MATERIALS}

\section{Mathematical Formulation}

The steady two-dimensional incompressible slip flow of Casson fluid bounded by a permeable stretching sheet at $y=0$, the flow being confined in $y>0$ were considered. The rheological equation of state for an isotropic and incompressible flow of a Casson fluid can be written as follows [31]:

$$
\tau_{i j}=\left\{\begin{array}{l}
\left(\mu_{B}+p_{y} / \sqrt{2 \pi}\right) 2 e_{i j}, \pi>\pi_{c} \\
\left(\mu_{B}+p_{y} / \sqrt{2 \pi}\right) 2 e_{i j}, \pi>\pi_{c}
\end{array}\right.
$$

where $\mu_{B}$ is plastic dynamic viscosity of the non-Newtonian fluid, $p_{y}$ is the yield stress of fluid, $\pi$ is the product of the component of deformation rate with itself, namely, $\pi=e_{i j} e_{i j}, e_{i j}$ is the $(\mathrm{i}, \mathrm{j})$-th component of the deformation rate and $\pi_{c}$ is the critical value of $\pi$ based on the non-Newtonian model. A variable magnetic field $B^{\prime}(x)=B_{0} e^{\frac{x}{2 L}}$ is applied normal to the sheet, $B_{0}$ being a constant [48].

The governing equations for this problem may be written in the usual notation as [25]:

$$
\begin{aligned}
& \frac{\partial u}{\partial x}+\frac{\partial v}{\partial y}=0 \\
& u \frac{\partial u}{\partial x}+v \frac{\partial u}{\partial y}=v\left(1+\frac{1}{\beta}\right) \frac{\partial^{2} u}{\partial y^{2}}-\frac{\sigma B^{\prime 2}}{\rho} u, \\
& u \frac{\partial T}{\partial x}+v \frac{\partial T}{\partial y}=\alpha \frac{\partial^{2} T}{\partial y^{2}}+\frac{(\rho c)_{P}}{(\rho c)_{f}}\left[D_{B} \frac{\partial C}{\partial y} \frac{\partial T}{\partial y}+\frac{D_{T}}{T_{\infty}}\left(\frac{\partial T}{\partial y}\right)^{2}\right], \\
& u \frac{\partial C}{\partial x}+v \frac{\partial C}{\partial y}=D_{B} \frac{\partial^{2} C}{\partial y^{2}}+\frac{D_{T}}{T_{\infty}} \frac{\partial^{2} T}{\partial y^{2}},
\end{aligned}
$$

where $u$ and $v$ are the velocity components in $x$ and $y$ directions respectively, $v=\frac{\mu}{\rho}$ is the kinematic viscosity, $\beta$ is the Casson parameter, $\sigma$ is the electrical conductivity, $B_{0}$ is the initial strength of magnetic field, $\rho_{f}$ is the density of the base fluid, $T$ is the temperature, $T_{\infty}$ is constant temperature of the fluid in the inviscid free stream, $\alpha$ is the thermal diffusivity, $(\rho c)_{p}$ is the effective heat capacity of nanoparticles, $(\rho c)_{f}$ is heat capacity of the base fluid, $C$ is nanoparticle volume fraction, $D_{B}$ is the Brownian diffusion coefficient and $D_{T}$ is the thermophoretic diffusion coefficient.

In this study, Buongiorno [19] model for nanofluid has been used in view of the fact that the nano-materials with very small sizes acquire individual physical and chemical properties. They are capable of flowing effortlessly without making any blockage to themselves as they are tiny enough to act likewise to liquid molecules [49]. So, the momentum equation for Casson nanofluid under boundary layer approximations remained the same as that of Casson fluid. Only due to the presence of nanoparticles, the Brownian motion and thermophoresis effect were exhibited through the last two terms of equation (3) and last term of equation (4). 
The associated conditions at the wall (boundary) are given by [45]

$$
\begin{gathered}
u=U_{w}+B_{1} v \frac{\partial u}{\partial y}, v=v_{w} \text { at } y=0 \text { and } u \rightarrow 0 \text { as } y \rightarrow \infty, \\
T=T_{w}+D_{1} \frac{\partial T}{\partial y} \text { at } y=0 \text { and } T \rightarrow T_{\infty} \text { as } y \rightarrow \infty, \\
C=C_{w}+N_{1} \frac{\partial C}{\partial y} \text { at } y=0 \text { and } C \rightarrow C_{\infty} \text { as } y \rightarrow \infty .
\end{gathered}
$$

where $U_{w}=a \exp \left(\frac{x}{L}\right)$ is the stretching velocity where $a>0$ is a constant which indicates stretching. $T_{w}$ is the temperature at the sheet, $T_{\infty}$ is the free stream temperature, $C_{w}$ is the wall nanoparticle volume fraction and $C_{\infty}$ is the nanoparticle volume fraction in free stream. $v_{w}$ is the variable velocity for suction/blowing with $v_{w}=v_{0} \exp \left(\frac{x}{2 L}\right)[6]$ where $v_{0}$ is a constant where $v_{0}>0$ indicates suction and $v_{0}<0$ stands for blowing. Here, the velocity slip factor $B_{1}$, thermal slip factor $D_{1}$ and mass slip factor $N_{1}$ are respectively given by $B_{1}=B_{1}^{\prime} \exp \left(\frac{-x}{2 L}\right), D_{1}=D_{1}^{\prime} \exp \left(\frac{-x}{2 L}\right), N_{1}=N_{1}^{\prime} \exp \left(\frac{-x}{2 L}\right)$ where $B_{1}^{\prime}, D_{1}^{\prime}, N_{1}^{\prime}$ are respectively the initial values of $B_{1}, D_{1}, N_{1}$.

Let us introduce the similarity variable $\eta$ and consider the similarity transformation given by

$$
\psi=\sqrt{2 v L a} f(\eta) \exp \left(\frac{x}{2 L}\right), \eta=y \sqrt{\frac{a}{2 v L}} \exp \left(\frac{x}{2 L}\right), \theta(\eta)=\frac{T-T_{\infty}}{T_{w}-T_{\infty}}, \phi(\eta)=\frac{C-C_{\infty}}{C_{w}-C_{\infty}}
$$

where $\psi$ is the stream function given by $u=\frac{\partial \psi}{\partial y}, v=-\frac{\partial \psi}{\partial x}$.

Equation (1) is automatically satisfied by this. Using the relation (6) in equations (2)-(4), we get the following equations

$$
\begin{aligned}
& f^{\prime \prime}\left(1+\frac{1}{\beta}\right)+f f f^{\prime \prime}-2 f^{2}-M^{2} f^{\prime}=0, \\
& \theta^{\prime \prime}+\operatorname{Pr}\left(f \theta^{\prime}+N_{b} \theta^{\prime} \phi^{\prime}+N_{t} \theta^{\prime 2}\right)=0, \\
& \phi^{\prime \prime}+\text { Le } f \phi^{\prime}+\frac{N_{t}}{N_{b}} \theta^{\prime \prime}=0 .
\end{aligned}
$$

Here $\mathrm{M}=\sqrt{\frac{2 \sigma B_{0}^{2} L}{\rho a}}$ is the magnetic parameter, $\operatorname{Pr}=\frac{v}{\alpha}$ is the Prandtl number and $L e=\frac{v}{D_{B}}$ is the Lewis number. The two dimensionless parameters $N_{b}$ (Brownian motion parameter) and $N_{t}$ (thermophoresis parameter) are defined as

$$
N_{b}=D_{B} \frac{(\rho c)_{p}}{(\rho c)_{f}} \frac{\left(C_{w}-C_{\infty}\right)}{v}, N_{t}=\frac{D_{T}}{T_{\infty}} \frac{(\rho c)_{p}}{(\rho c)} \frac{\left(T_{w}-T_{\infty}\right)}{v} \text {. }
$$


The boundary condition takes the following forms

$$
\begin{aligned}
& f(\eta)=\mathrm{S}, f^{\prime}(\eta)=1+\mathrm{B} f^{\prime \prime}(\eta) \text { at } \eta=0, \\
& f^{\prime}(\eta) \rightarrow 0 \text { as } \eta \rightarrow \infty \\
& \theta(\eta)=1+\mathrm{D} \theta^{\prime}(\eta) \text { at } \eta=0, \\
& \theta(\eta) \rightarrow 0 \text { as } \eta \rightarrow \infty \\
& \phi(\eta)=1+\mathrm{N} \phi^{\prime}(0) \text { at } \eta=0, \\
& \phi(\eta) \rightarrow 0 \text { as } \eta \rightarrow \infty
\end{aligned}
$$

where $\mathrm{S}=-\frac{v_{0}}{\sqrt{(v c) /(2 L)}}$ is the suction/blowing parameter. Here, $\mathrm{S}>0 \quad\left(v_{0}<0\right)$

corresponds to suction and $\mathrm{S}<0\left(v_{0}>0\right)$ corresponds to blowing. $\mathrm{B}, \mathrm{D}, \mathrm{N}$ are respectively the velocity slip, thermal slip and mass slip parameters given by $B=B_{1}^{\prime} \sqrt{\frac{a v}{2 L}}, D=D_{1}^{\prime} \sqrt{\frac{a}{2 v L}}, N=N_{1}^{\prime} \sqrt{\frac{a}{2 v L}}$.

The local skin friction coefficient $\mathrm{C}_{\mathrm{f}}$, local Nusselt number $\mathrm{Nu}_{\mathrm{x}}$ and local Sherwood number $\mathrm{Sh}_{\mathrm{x}}$ are the quantities of physical interest for this problem which are given by $\quad C_{f}=\left.\frac{v}{U_{w}{ }^{2}} \frac{\partial u}{\partial y}\right|_{y=0}, N u_{x}=-\left.\frac{x}{\left(T_{w}-T_{\infty}\right)} \frac{\partial T}{\partial y}\right|_{y=0}, S h_{x}=-\left.\frac{x}{C_{w}-C_{\infty}} \frac{\partial C}{\partial y}\right|_{y=0}$

i.e. $\sqrt{2 \operatorname{Re}_{x} C_{f}}=f^{\prime \prime}(0), \frac{N u_{x}}{\sqrt{2 \operatorname{Re}_{x}}}=-\sqrt{\frac{x}{2 L}} \theta^{\prime}(0), \frac{S h_{x}}{\sqrt{2 \mathrm{Re}_{x}}}=-\sqrt{\frac{x}{2 L}} \phi^{\prime}(0)$, $\operatorname{Re}_{x}=\frac{U_{w} x}{v}$ being the local Reynolds number.

The highly nonlinear coupled ODEs (7-9) along with boundary conditions (10a$12 \mathrm{~b}$ ) form a two point boundary value problem (BVP) were solved using the shooting method.

\section{RESULTS AND DISCUSSION}

To validate the accuracy of the numerical method used in this problem, a special case of fluid with a very large value of Casson parameter in the absence of magnetic field, suction/blowing and slips at the boundary (i.e. $M=0, S=0, B=0, D=0, N=0$ ) was considered and comparison was made for the value of velocity gradient at the wall [ $f^{\prime \prime}(0)$ ] with the available published results of Magyari and Keller [5], Elbashbeshy [6], Sahoo and Poncet [42]. The results were found to be in excellent agreement.

Table 1. Value of [ $f^{\prime \prime}(0)$ ] related to the skin friction coefficient for Newtonian fluid.

\begin{tabular}{cccc}
\hline Magyari and Keller [5] & Elbashbeshy [6] & Sahoo and Poncet [42] & Present study \\
-1.28180 & -1.28181 & -1.281811 & -1.281812 \\
\hline
\end{tabular}

Our results for ordinary viscous Newtonian fluid in the absence of magnetic field, suction/blowing and slips at the boundary for constant surface temperature (CST) agree with the results of Magyari and Keller [5] (see, Table 2]. Moreover our results for heat transfer case for viscous Newtonian fluid were compared with the available results of 
Magyari and Keller [5], Ishak [48], Mandal and Mukhopadhyay [9] for prescribed surface temperature (PST) i.e. when $\left.T_{w}=T_{\infty}+T_{0} e^{\frac{x}{2 L}}\right]$ and the results corresponding to heat transfer coefficient $\left[-\theta^{\prime}(0)\right]$ agree well with their results [Table 1] [9]. Basically, when Casson parameter $\beta$ becomes very large, the fluid behaves as Newtonian fluid which can be easily viewed from the governing equation (2). Moreover, the fluid behaves as an ordinary viscous fluid if $N_{b}=0=N_{t}$. Here, $\mathrm{M}=0$ indicates that the results were obtained in the absence of magnetic field. Under these specific conditions (as in the studies of Magyari and Keller [5], Ishak [48], and Mandal and Mukhopadhyay [9] which are related to ordinary viscous Newtonian fluid), our results for prescribed surface temperature case (i.e. when $T_{w}=T_{\infty}+T_{0} e^{\frac{x}{2 L}}$ ) match completely with the available results in open literature which can be viewed from Table 2 .

Table 2. Values of $\left[-\theta^{\prime}(0)\right]$ for several values of Prandtl number (Pr) for constant surface temperature [CST] and for prescribed surface temperature [PST].

\begin{tabular}{|c|c|c|c|c|c|c|}
\hline \multirow[t]{2}{*}{$\operatorname{Pr}$} & \multirow{2}{*}{$\begin{array}{c}\text { Present study } \\
\text { (for } \mathrm{M}=0, \mathrm{~S}=0, \\
\mathrm{~B}=\mathrm{D}=0, \\
\beta \rightarrow \infty, N_{b}=0, \\
\left.N_{t}=0\right) \\
(\mathrm{CST})\end{array}$} & \multicolumn{2}{|c|}{$\begin{array}{c}\text { Magyari and } \\
\text { Keller [5] }\end{array}$} & \multirow{2}{*}{$\begin{array}{c}\text { Ishak } \\
\text { [48] } \\
\text { (PST) }\end{array}$} & \multirow{2}{*}{$\begin{array}{c}\text { Mandal and } \\
\text { Mukhopadhyay } \\
\text { [9] (PST) }\end{array}$} & \multirow{2}{*}{$\begin{array}{c}\text { Present study } \\
\text { (for } \mathrm{M}=0, \mathrm{~S}=0, \\
\mathrm{~B}=\mathrm{D}=0, \\
\beta \rightarrow \infty, N_{b}=0, \\
\left.N_{t}=0\right) \\
(\mathrm{PST})\end{array}$} \\
\hline & & (CST) & (PST) & & & \\
\hline 1 & 0.549642 & 0.549643 & 0.9548 & 0.9548 & 0.9547 & 0.9547 \\
\hline 2 & & & & 1.4715 & 1.4714 & 1.4714 \\
\hline 3 & 1.122178 & 1.122188 & 1.8691 & 1.8691 & 1.8691 & 1.8691 \\
\hline 5 & 1.521229 & 1.521243 & 2.5001 & 2.5001 & 2.5001 & 2.5001 \\
\hline
\end{tabular}

This provides us with confidence to carry on the numerical results for the variations of the other parameters. In view of illustrating the salient features of this investigation, numerical results are presented through graphs in Figure 1(a-c) which were analysed one by one in detail as follows.

Figure 1(a)-(c) depict the effects of Casson fluid parameter on velocity, temperature and concentration respectively. From Figure 1(a), it was found that the velocity decreased with the increase of Casson fluid parameter in the presence of magnetic field. Due to the increase in $\beta$ plastic dynamic, viscosity increased and it caused resistance to the fluid motion [36]. As a result, momentum of boundary layer thickness reduced with the rise in Casson parameter [31, 50]. Fluid velocity was much more suppressed in the case of suction $(S=0.5)$ than that of blowing $(S=-0.5)$ [Figure 1(a)]. The effects of Casson fluid parameter on temperature and concentration are shown in Figure1(b-c). Both increased with the increasing of Casson fluid parameter $\beta$. Consequently, the temperature and concentration boundary layer thickness both increased. Due to the increase in elasticity, stress parameter thickening of the thermal and solutal boundary layers occurred [31]. 


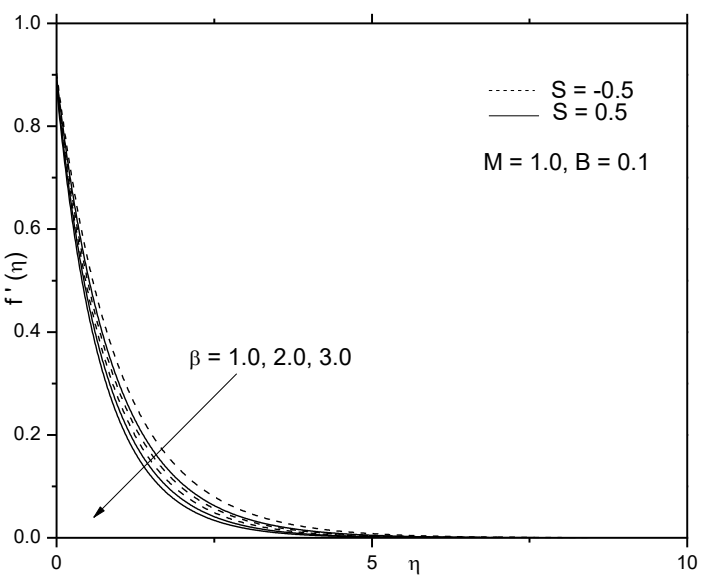

(a)

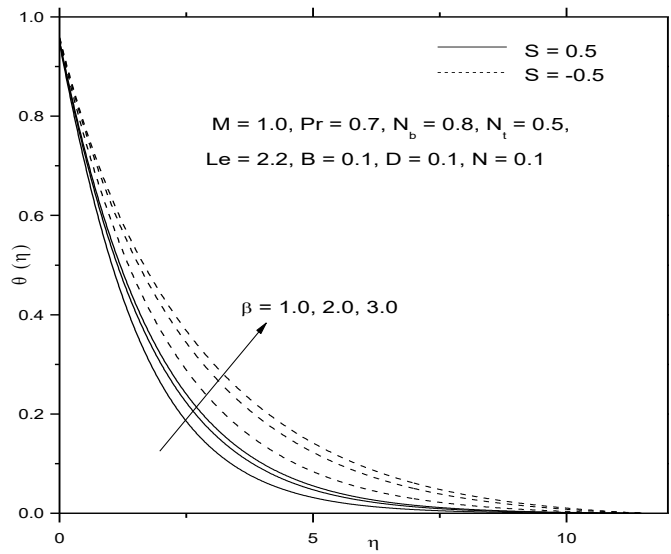

(b)

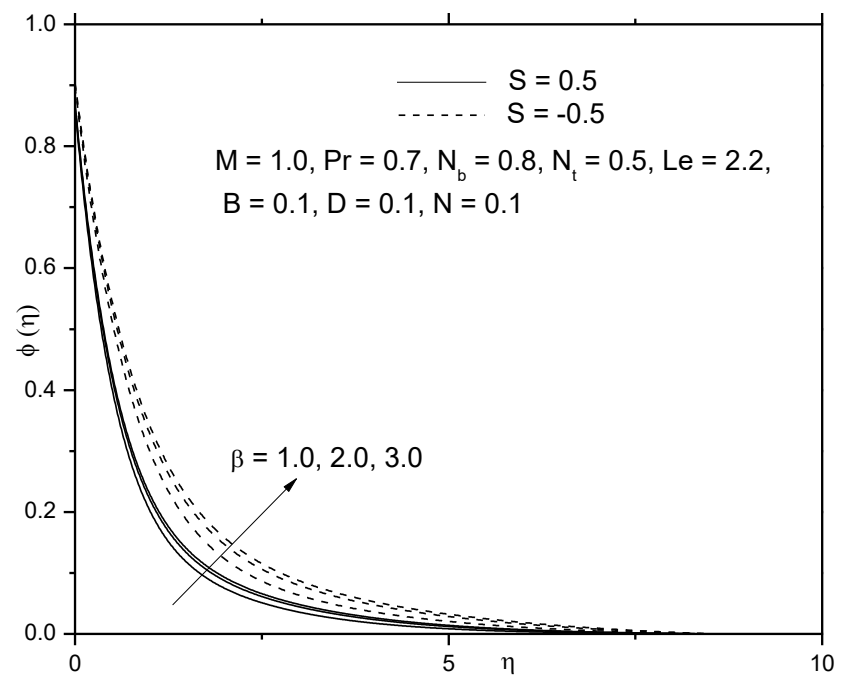

(c)

Figure 1. Effects of Casson parameter $\beta$ on (a) velocity $f^{\prime}(\eta)$ (b) temperature $\theta(\eta)$ and (c) nanoparticle volume fraction $\phi(\eta)$

Figure 2(a)-(c) present the effects of mass suction parameter on velocity, temperature and concentration field respectively. It was found that the velocity [Figure 2(a)], temperature [Figure 2(b)] and nanoparticle volume fraction [Figure 2(c)] decreased with the increase of mass suction parameter. The flow was closer to the boundary layer due to the increase of mass suction [50]. Thus, the velocity boundary layer thickness became thinner [Figure 2(a)]. The same type of effect was noted for the thermal [Figure 2(b)] and nanoparticle volume [Figure 2(c)] boundary layer thicknesses. On the other hand, the opposite effect was observed for the blowing case; due to the increase of blowing, the velocity, thermal and nanoparticle volume boundary layer thicknesses increased [51]. This can be explained as follows. When stronger blowing was provided, the heated fluid was pushed further from the wall and so the fluid was accelerated. Due to the increase in magnetic parameter M, fluid velocity decreased [Figure 3(a)] but the temperature [Figure 3(b)] and concentration [Figure 3(c)] increased with the increase in magnetic field. 


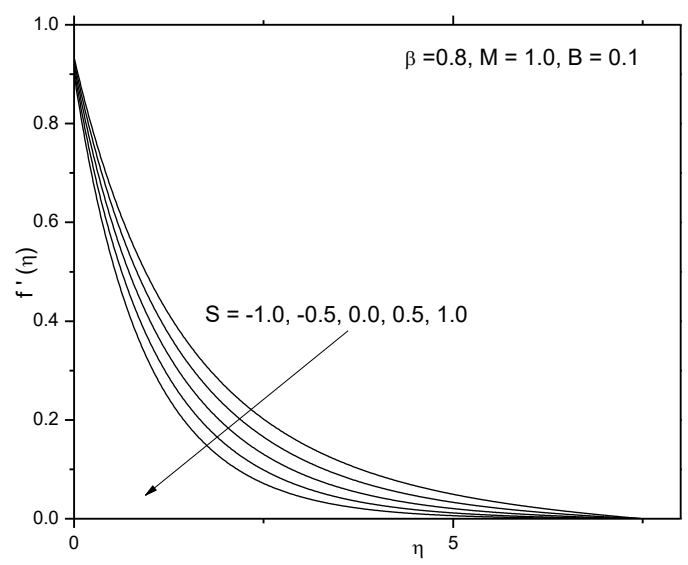

(a)

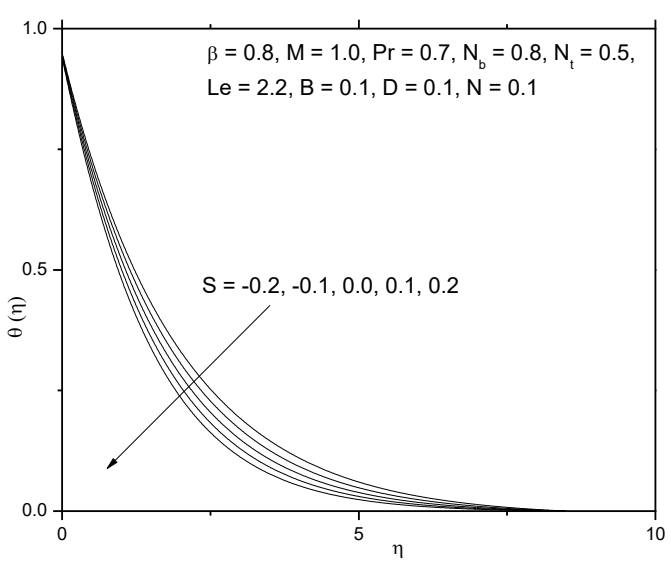

(b)

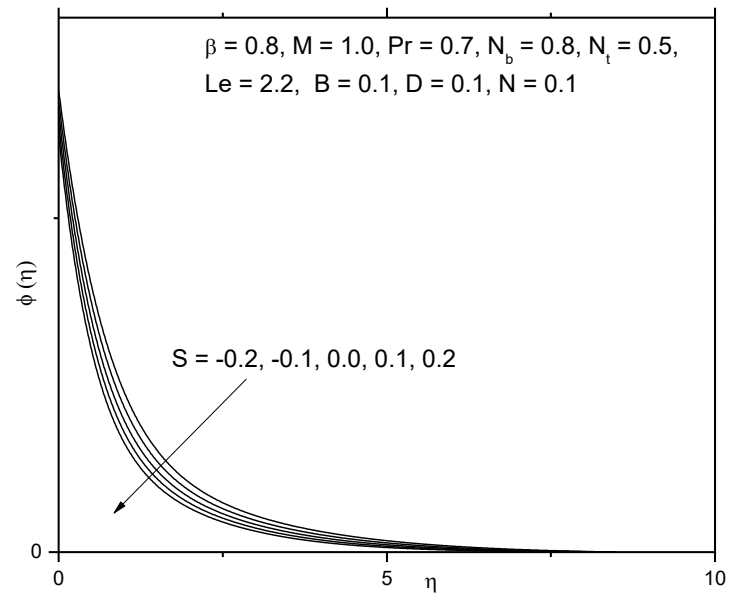

(c)

Figure 2. Effects of mass suction parameter S on (a) velocity $f^{\prime}(\eta)(\mathrm{b})$ temperature $\theta(\eta)$ and (c) nanoparticle volume fraction $\phi(\eta)$.

Application of a magnetic field normal to the direction of fluid flow gives rise to a resistive force (called the Lorentz force). Due to a rise in magnetic parameter $M$ this force increases. As it acts in the opposite direction of flow, it has a tendency to slow down the movement of the nanofluid [34]. Moreover, this force enhances thermal and solutal boundary layer thickness but diminishes the momentum boundary layer thickness. The effect of velocity slip parameter B is shown in Figure 4(a). It was found that with increasing velocity slip, fluid velocity decreased and so the velocity boundary layer thickness decreased [Figure 4(a)]. Due to slip, the flow velocity near the sheet was no longer equal to the stretching velocity at the sheet. With the increase in B, such slip velocity increased and consequently, fluid velocity decreased because under the slip condition at the boundary, the pulling of the stretching sheet can only be partly transmitted to the fluid [1]. Figure 4(b) shows that with the increase of thermal slip parameter, less heat was transferred to the fluid. As a result, temperature decreased. So, the thermal boundary layer thickness also decreased with the increase of thermal slip parameter. In Figure 4(c), the variations of temperature and nanoparticle volume fraction due to the variation in nanoparticle volume slip parameter $\mathrm{N}$ are exhibited. Nanoparticle volume fraction decreased significantly with the increase of nanoparticle volume slip parameter near the sheet [Figure 4(b)] but away from the sheet, this effect was not significant. So, 
the boundary layer thicknesses of temperature and nanoparticle volume fraction decreased.

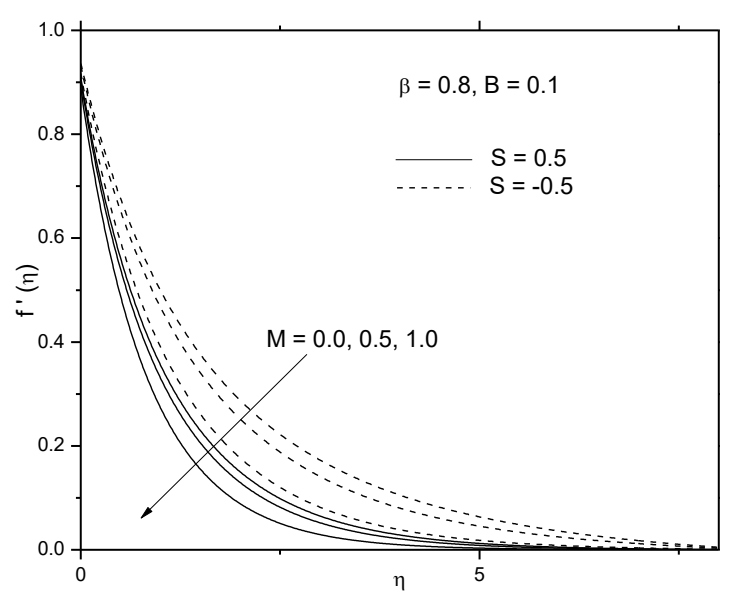

(a)

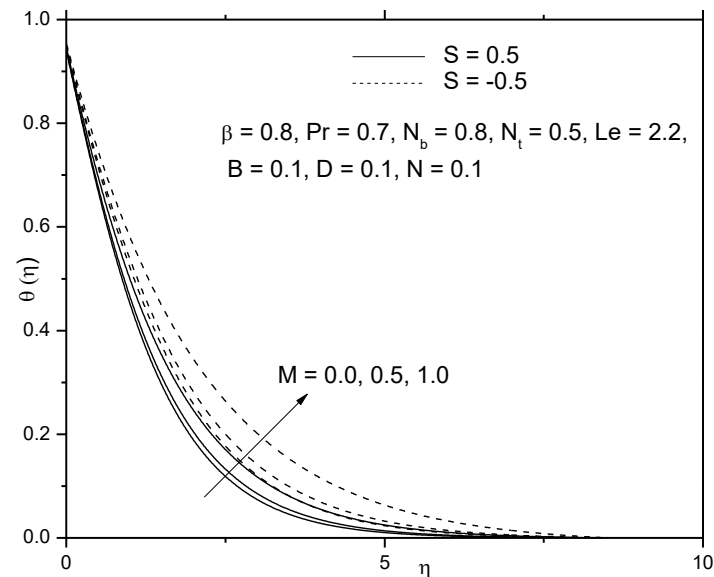

(b)

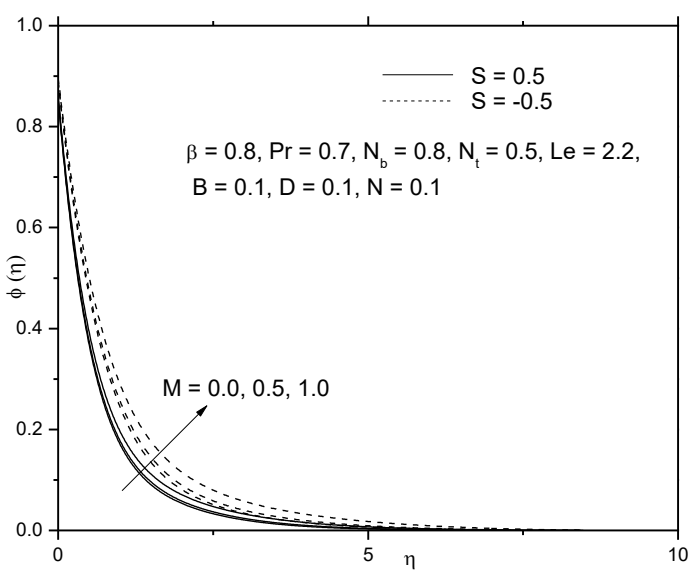

(c)

Figure 3. Effects of magnetic parameter M on (a) velocity $f^{\prime}(\eta)$ (b) temperature $\theta(\eta)$ and (c) nanoparticle volume fraction $\phi(\eta)$.

The effects due to the Brownian motion parameter $N_{b}$ are exhibited in Figure 5(a)-(b). Due to the increase of Brownian motion parameter, temperature increased and the thermal boundary layer thickened [Figure 5(a)]. But, the opposite behaviour was observed in the case of nanoparticle volume fraction [Figure 5(b)]. With the rise in $N_{b}$, nanoparticle volume boundary layer thickness decreased.

From Figure 6(a)-(b), effects due to thermophoresis parameter $N_{t}$ on temperature and nanoparticle volume fraction were observed. Due to the increase of thermophoresis parameter, both the temperature [Figure 6(a)] and nanoparticle volume fraction [Figure 6(b)] increased significantly [1]. Actually, with the increase in $N_{t}$, thermophoresis force increased and this helped to move the nanoparticles from hot to cold areas. As a result, both the temperature and concentration increased. 


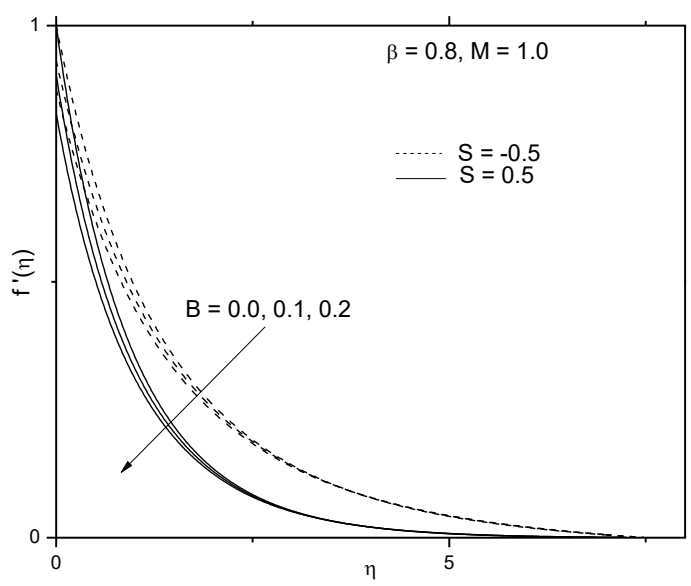

(a)

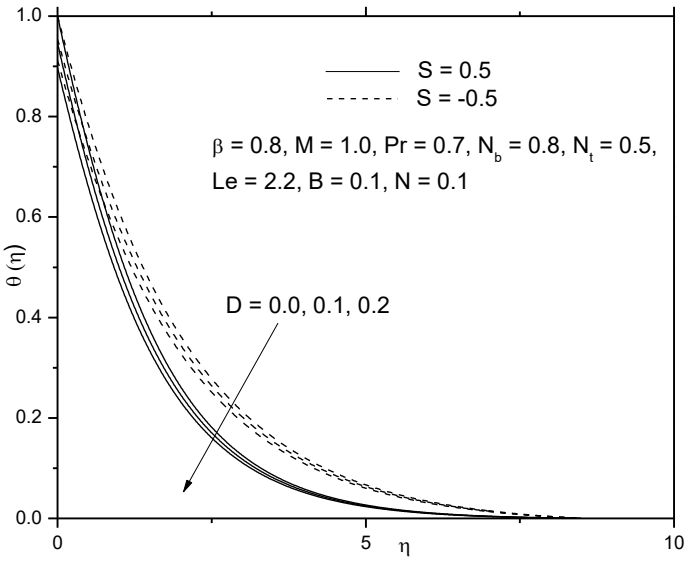

(b)

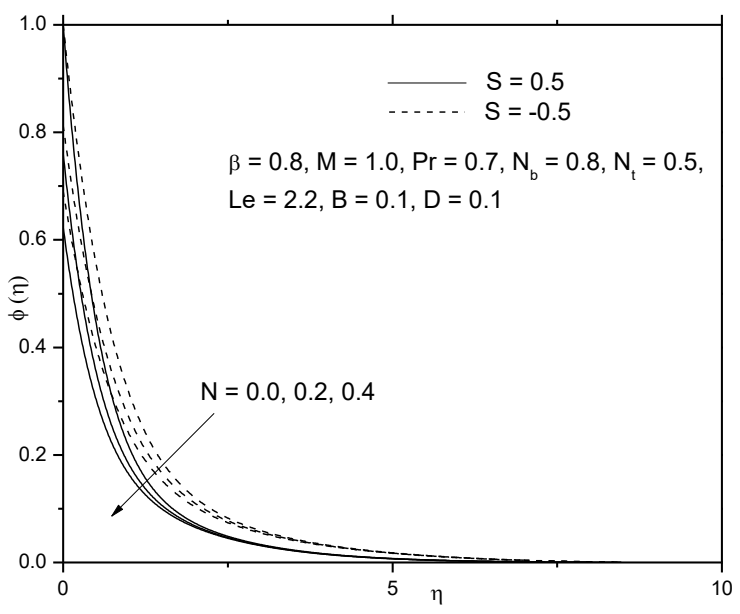

(c)

Figure 4. Effects of (a)velocity slip parameter $S$ on velocity $f^{\prime}(\eta)(b)$ thermal slip parameter $\mathrm{D}$ on temperature $\theta(\eta)$ and (c) nanoparticle volume slip parameter $\mathrm{N}$ on nanoparticle volume fraction $\phi(\eta)$.

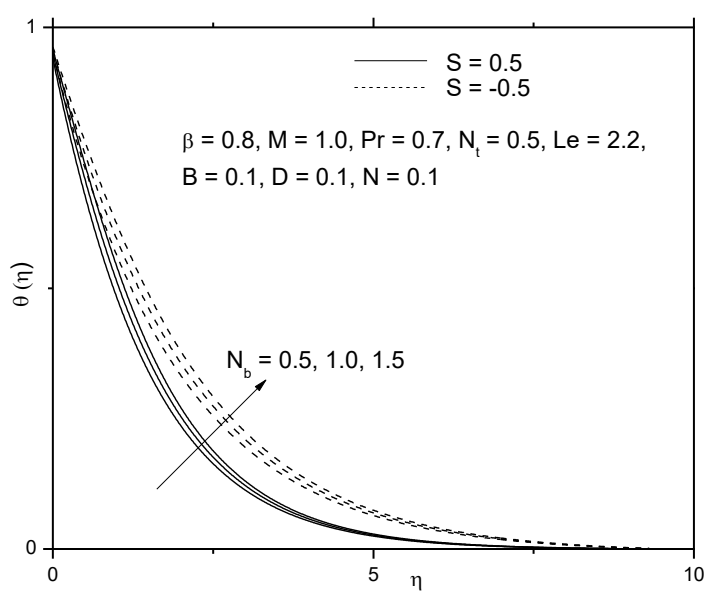

(a)

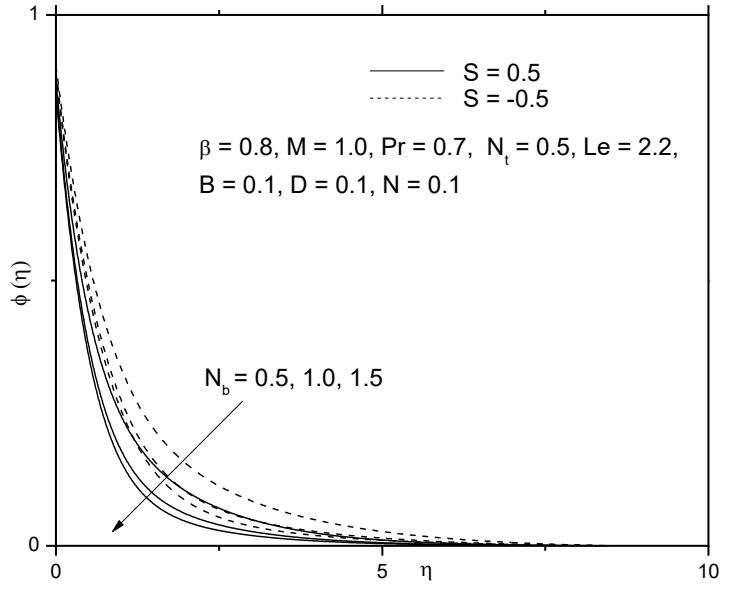

(b)

Figure 5. Effects of Brownian motion parameter $\mathrm{N}_{\mathrm{b}}$ on (a) temperature $\theta(\eta)$ and (b) nanoparticle volume fraction $\phi(\eta)$. 


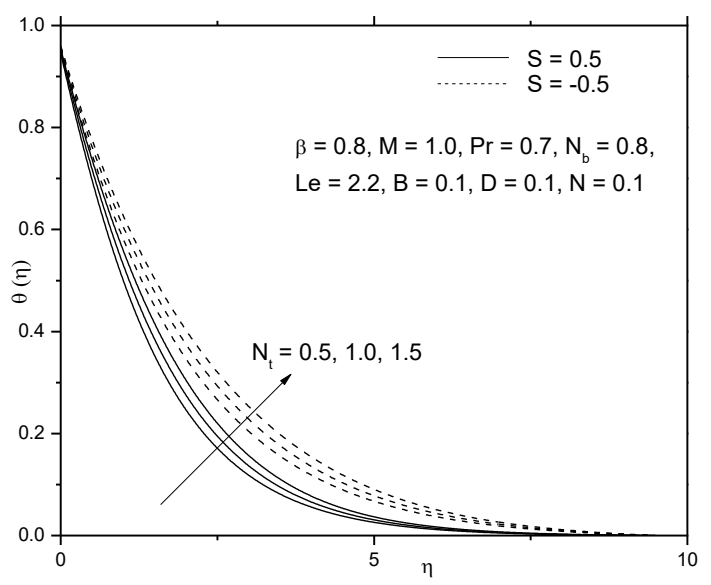

(a)

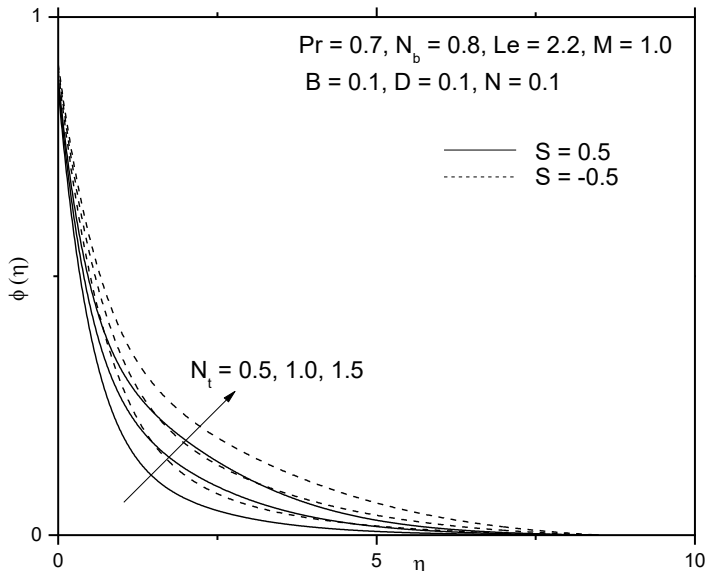

(b)

Figure 6. Effects of thermophoresis parameter $\mathrm{N}_{\mathrm{t}}$ on (a) temperature $\theta(\eta)$ and (b) nanoparticle volume fraction $\phi(\eta)$.

The effects of Prandtl number Pr are exhibited in Figure 7(a)-(b). Temperature decreased with the increasing Pr and thermal boundary layer thickness decreased [Figure7(a)]. Nanoparticle volume fraction initially increased with the increasing $\operatorname{Pr}$ [Figure 7(b)] but away from the sheet, it decreased. This was due to the Brownian motion of the nanoparticles. So, the thermal and concentration boundary layer thicknesses decreased in both cases. Actually, fluid with higher Prandtl number had lower thermal conductivity which caused the decrease of the thickness of thermal boundary layer.

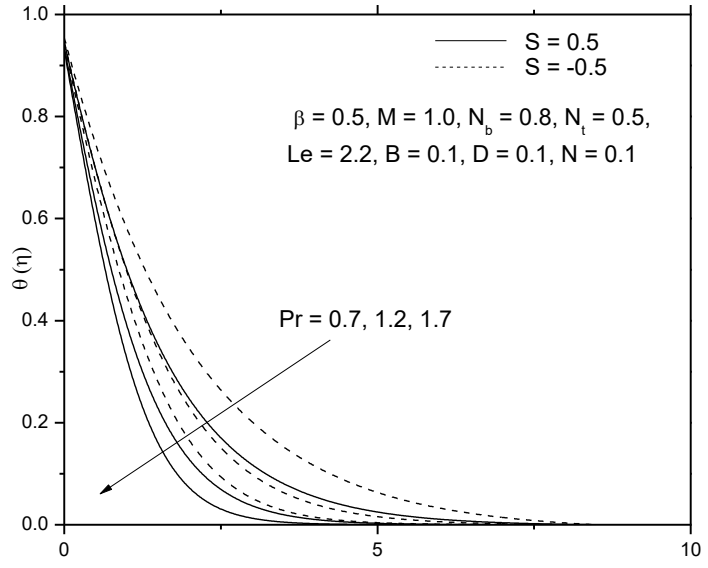

(a)

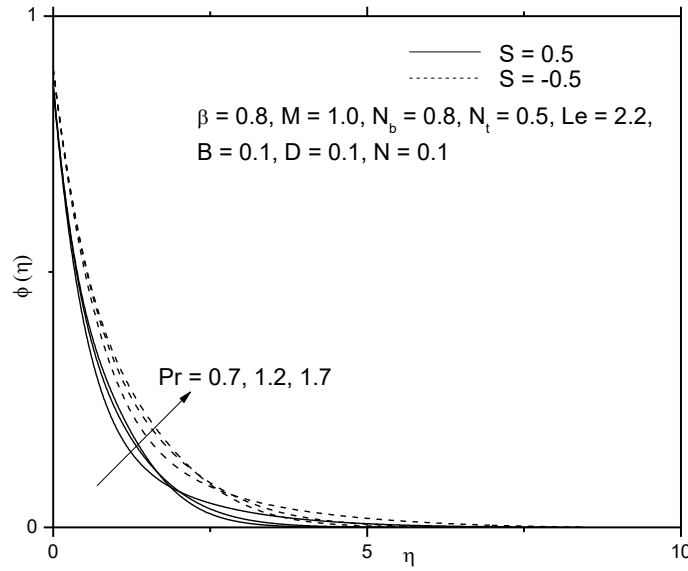

(b)

Figure 7. Effects of Prandtl number Pr on (a) temperature $\theta(\eta)$ and (b) nanoparticle volume fraction $\phi(\eta)$.

Fluid temperature decreased with the increasing values of Lewis number Le [Figure 8(a)]. But this effect was not so significant. Nanoparticle volume fraction was also found to decrease significantly with the increasing Lewis number Le [Figure 8(b)]. With the increase in Le, mass transfer rate increased and consequently, concentration boundary layer thickness decreased. For a specific base fluid, if Le increased, then Brownian diffusion coefficient $D_{B}$ decreased. As a result, the penetration depth of the concentration boundary layer decreased. 


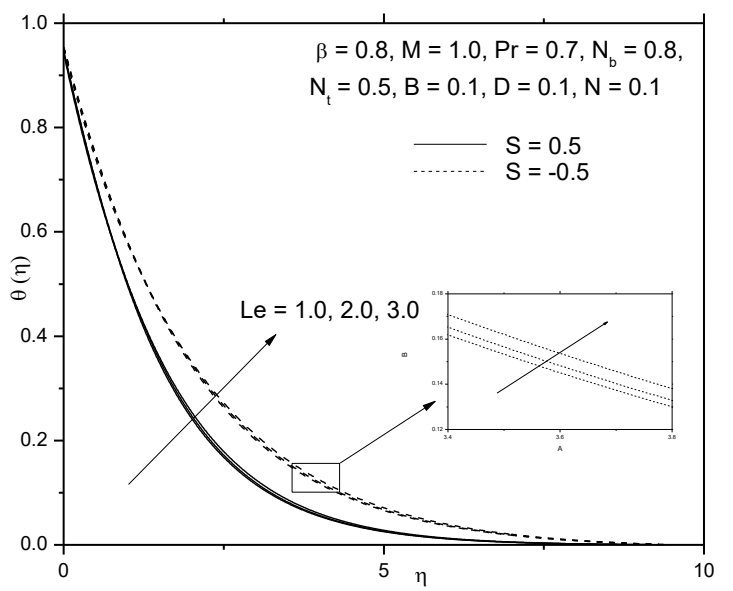

(a)

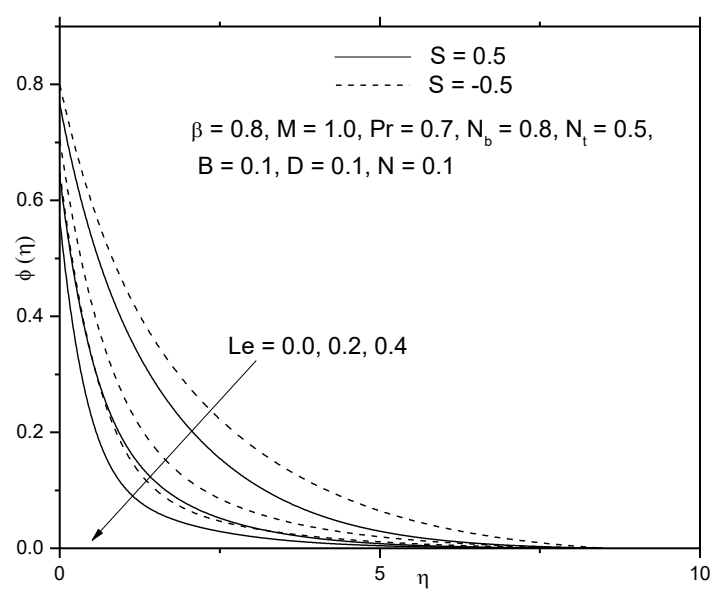

(b)

Figure 8. Effects of Lewis number Le on (a) temperature $\theta(\eta)$ and (b) nanoparticle volume fraction $\phi(\eta)$.

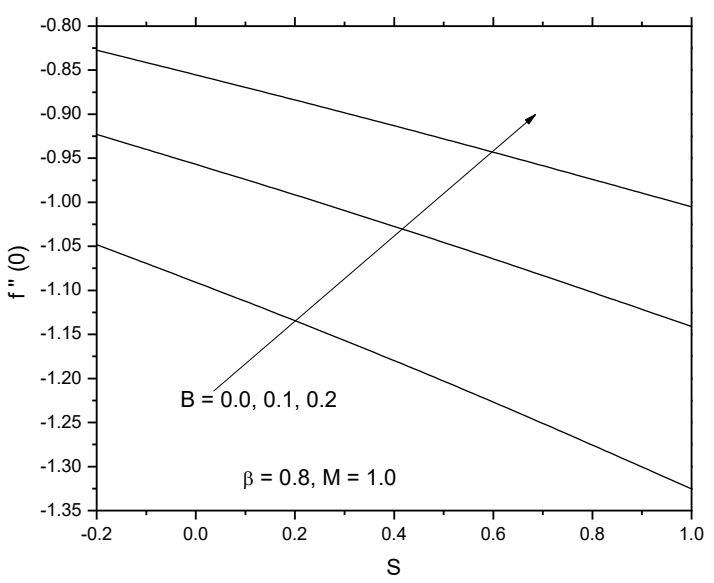

(a)

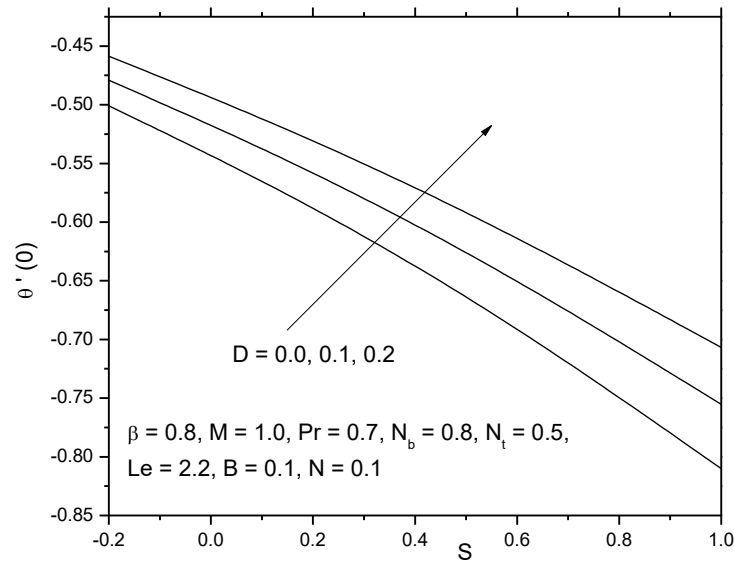

(b)

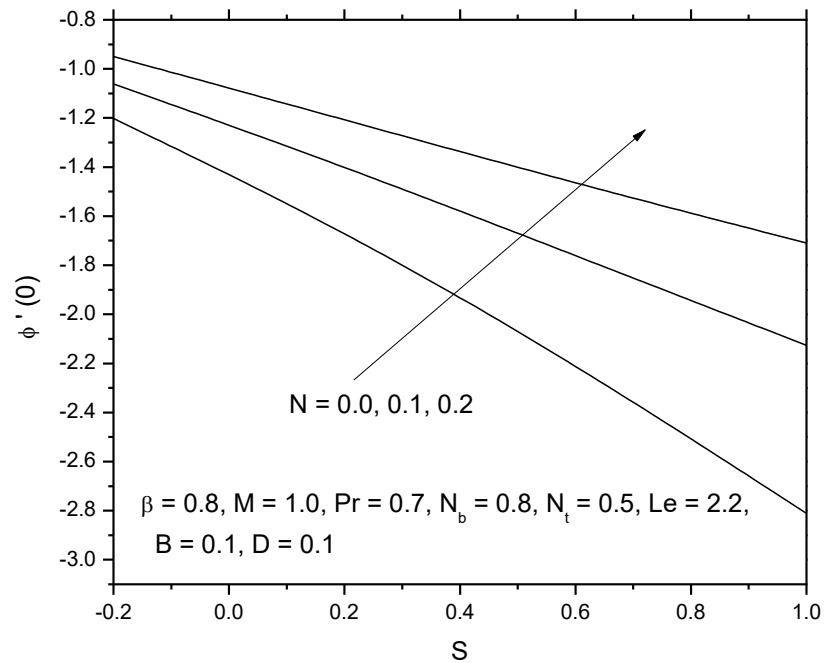

(c)

Figure 9. Variations of (a) $f^{\prime \prime}(0)$ with mass suction parameter $\mathrm{S}$ for different values of velocity slip parameter B (b) $\theta^{\prime}(0)$ with mass suction parameter $\mathrm{S}$ for different values of thermal slip parameter $\mathrm{D}$ and (c) $\phi^{\prime}(0)$ with mass suction parameter $\mathrm{S}$ for different values of nanoparticle volume slip parameter $\mathrm{N}$ for different values of mass transfer parameter $\mathrm{S}$. 


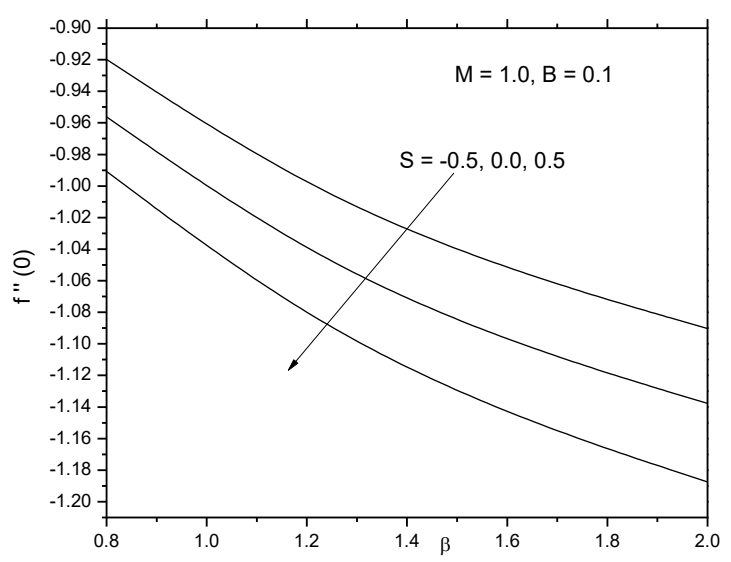

(a)

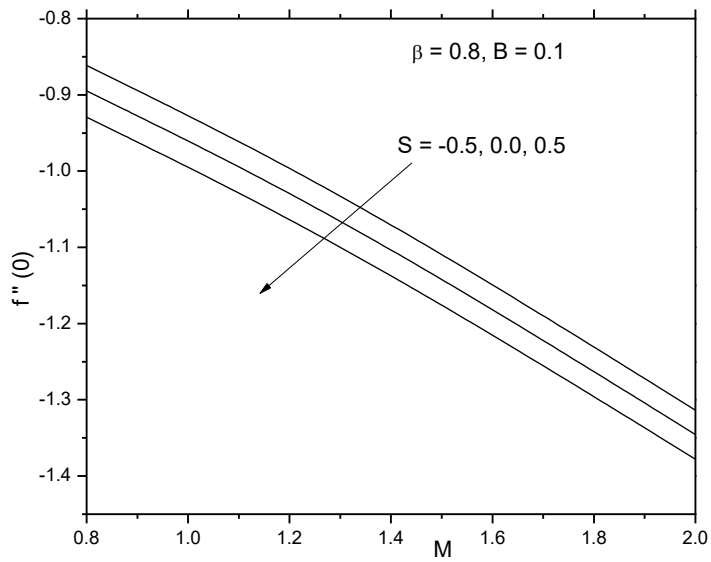

(b)

Figure 10. Variations of $f^{\prime \prime}(0)$ with (a) Casson parameter $\beta$ (b) magnetic parameter $\mathrm{M}$ for different values of mass suction parameter $\mathrm{S}$.

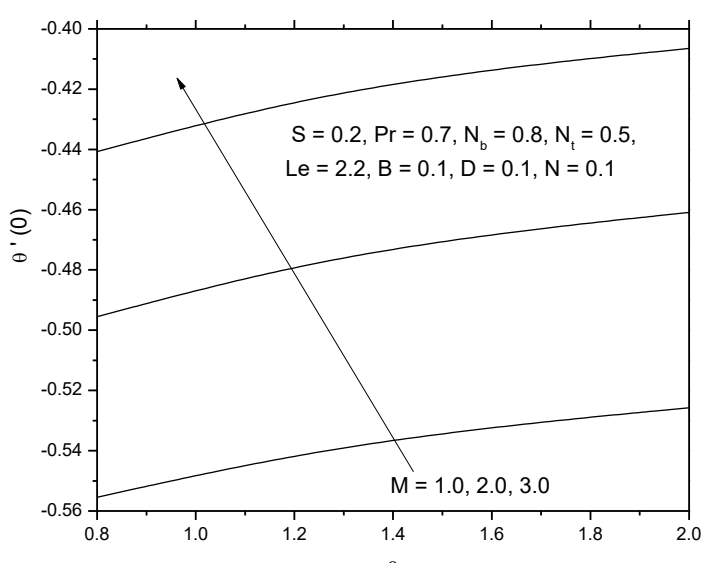

(a)

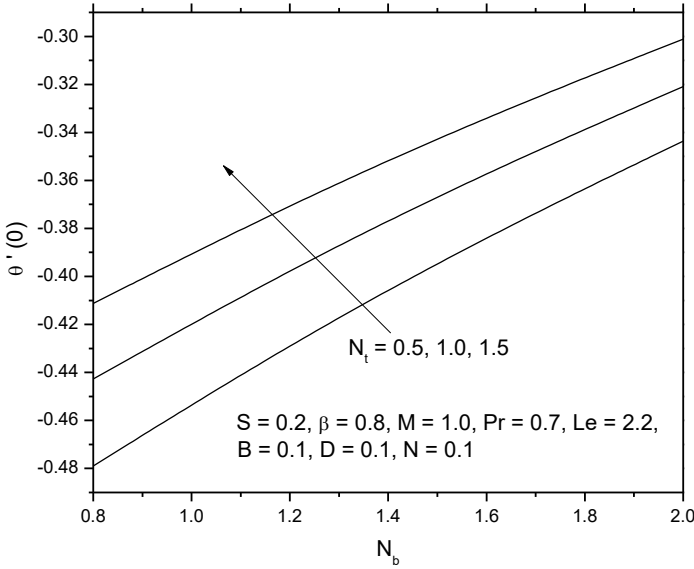

(b)

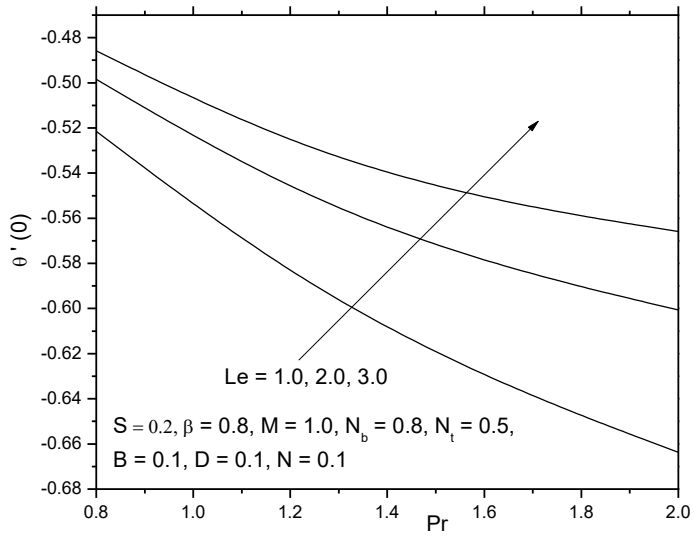

(c)

Figure 11. Variations of $\theta^{\prime}(0)$ with (a) Casson parameter $\beta$ for different values of magnetic parameter $M$ (b) Brownian motion parameter $N_{b}$ for different values of thermophoresis parameter $\mathrm{N}_{\mathrm{t}}$ (c) Prandtl number Pr for different values of Lewis number Le. 
The effects of velocity, thermal and mass slip parameter and mass suction parameter $S$ on velocity, temperature and concentration gradient are shown in Figure 9(ac). The velocity gradient at the wall $\left[f^{\prime \prime}(0)\right]$ increased for increasing velocity slip parameter B and decreased for mass suction parameter $S$ [Figure 9(a)]. Negative values of $f^{\prime \prime}(0)$ indicated that the drag force was exerted by the sheet on the fluid. It was observed that temperature gradient at the wall $\left[\theta^{\prime}(0)\right]$ increased for the increasing thermal slip parameter D and decreased for mass suction parameter $S$ [Figure 9(b)]. Similarly, the concentration gradient at the wall $\left[\phi^{\prime}(0)\right]$ increased for the increasing mass slip parameter $\mathrm{N}$ and decreased for mass suction parameter $\mathrm{S}$ [Figure 9(c)].

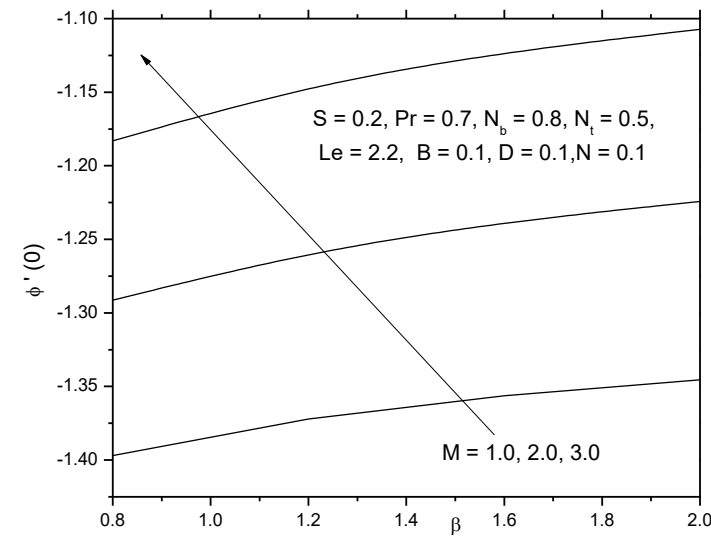

(a)

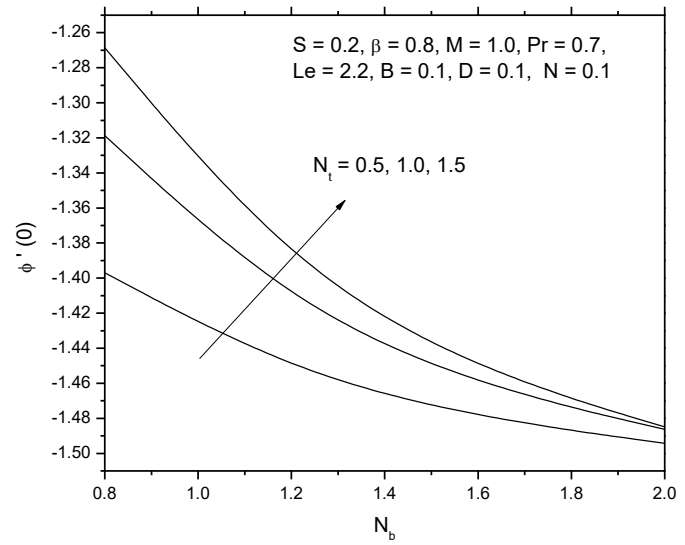

(b)

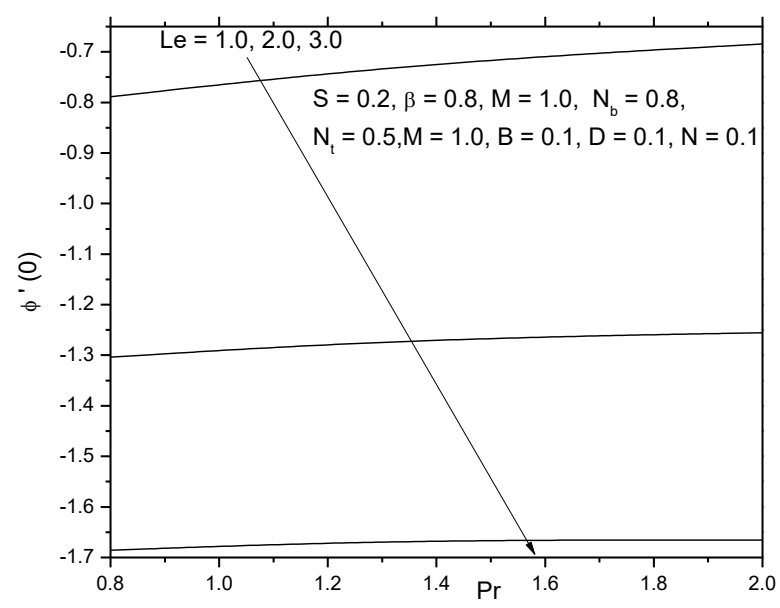

(c)

Figure 12. Variations of $\phi^{\prime}(0)$ with (a) Casson parameter $\beta$ for different values of magnetic parameter $M$ (b) Brownian motion parameter $N_{b}$ for different values of thermophoresis parameter $\mathrm{N}_{\mathrm{t}}$ (c) Prandtl number Pr for different values of Lewis number Le.

From Figure 10(a)-(b), it was found that velocity gradient at the wall $\left[f^{\prime \prime}(0)\right]$ decreased with the increasing values of Casson fluid parameter $\beta$ [Figure 10(a)]. For this, Casson fluid model was used in the industry to predict the high shear rate viscosities. Actually, Casson fluid parameter $\beta$ is inversely proportional to the yield stress. So, 
increase in $\beta$ means a decrease in yield stress. Velocity gradient at the wall [ $\left.f^{\prime \prime}(0)\right]$ also decreased with the increasing magnetic parameter M [Figure 10(a)]. It is obvious that due to higher values of magnetic parameter, Lorentz force was enhanced, leading to more and more resistance to the fluid motion which resulted in the reduction of momentum boundary layer thickness. Velocity gradient at the wall $\left[f^{\prime \prime}(0)\right]$ also decreased with the increasing strength of mass suction parameter S [Figure 10(b)], implying that less force is necessary for the pulling of a sheet for a specific withdrawal velocity. It can be interpreted also as: For a specific driving force, higher withdrawal velocity can be achieved. It can increase the rate of production, which has great importance in free coating operations.

The temperature gradient at the wall $\left[\theta^{\prime}(0)\right]$ increased with the Casson parameter $\beta$ and also with the magnetic parameter M [Figure 11(a)]. Ohmic heating due to magnetic field influenced the surface temperature as well as the surface temperature gradient. Figure 11(b) shows that temperature gradient at the wall $\left[\theta^{\prime}(0)\right]$ increased with the Brownian motion parameter $\mathrm{N}_{\mathrm{b}}$ and also with thermophoresis parameter $\mathrm{N}_{\mathrm{t}}$. Due to thermophoresis, nanoparticles acquired a velocity in the direction in which the temperature of the nanofluid decreased [51]. So, due to the increase in $\mathrm{N}_{\mathrm{t}}$, temperature difference between the sheet and the ambient fluid increased. As a result, thermal boundary layer thickness increased. With the Lewis number Le, the temperature gradient at the wall $\left[\theta^{\prime}(0)\right]$ increased but decreased with Prandtl number Pr [Figure 11(c)]. With increasing Pr, thermal conductivity of the fluid reduced and as a result, thermal boundary layer thickness decreased. Temperature gradient at the wall was always negative which indicated that heat was transferred from the sheet to the ambient fluid. From Figure 12(a), it was observed that $\phi^{\prime}(0)$ increased with the Casson parameter $\beta$ and also with the magnetic parameter M. $\phi^{\prime}(0)$ decreased with the Brownian motion parameter $\mathrm{N}_{\mathrm{b}}$. This implied that due to the Brownian motion of nanoparticles, mass transfer of nanofluid decreased. But $\phi^{\prime}(0)$ increased with the increasing thermophoresis parameter $\mathrm{Nt}$ [Figure 12(b)]. With the increasing of Lewis number Le, mass diffusivity decreased and so $\phi^{\prime}(0)$ decreased but $\phi^{\prime}(0)$ increased with the increasing Prandtl number $\operatorname{Pr}$ [Figure 12(c)].

\section{CONCLUSIONS}

A numerical study was presented to discuss the effects of slip on Casson nanofluid flow and heat transfer past an exponentially stretching permeable sheet in the presence of a magnetic field. Similarity solutions of the governing equations were obtained. Based on the observations, the following conclusions can be made.

(i) Effect of Casson parameter was to suppress the velocity field whereas the temperature and concentration of nanofluid increase dwith the increase in Casson parameter.

(ii) Momentum boundary layer thickness decreased with the increasing magnetic field intensity. Magnetic parameter reduced the skin friction coefficient, heat flux and mass flux coefficients.

(iii) Fluid velocity was higher for blowing compared to that of suction.

(iv) Skin friction coefficient increased with the increasing velocity of slip parameter, heat transfer coefficient increased with the increasing thermal slip 
parameter and mass transfer coefficient was found to increase with the increase in mass slip parameter.

(v) Nusselt number was found to increase with the increasing Brownian motion parameter as well as with the increasing thermophoresis parameter.

(vi) Mass transfer decreased due to Brownian motion parameter but it increased with the increase in thermophoresis parameter.

Such flow can provide immense help in cancer therapy, polishing of internal cavities and valves as well as for cleaning oil from surfaces.

\section{ACKNOWLEDGEMENTS}

One of the author Mr. S. Ghosh would like to be obliged to CSIR, New Delhi, India for providing the financial assistance to carry on research work and other author Dr. S. Mukhopadhyay wishes to express appreciation to SERB, New Delhi, India for financial support received through Young Scientist Project (YSS/2014/000681). The authors are thankful to the reviewers for the useful suggestions.

\section{REFERENCES}

[1] Das K. Nanofluid flow over a non-linear permeable stretching sheet with partial slip. Journal of the Egyptian Mathematical Society. 2015;23:451-6.

[2] Zeeshan A, Majeed A, Ellahi R. Effect of magnetic dipole on viscous ferro-fluid past a stretching surface with thermal radiation. Journal of Molecular liquids. 2016;215:549-54.

[3] Crane LJ. Flow past a stretching plate. Zeitschrift für angewandte Mathematik und Physik ZAMP. 1970;21:645-7.

[4] Gupta P, Gupta A. Heat and mass transfer on a stretching sheet with suction or blowing. The Canadian Journal of Chemical Engineering. 1977;55:744-6.

[5] Magyari E, Keller B. Heat and mass transfer in the boundary layers on an exponentially stretching continuous surface. Journal of Physics D: Applied Physics. 1999;32:577.

[6] Elbashbeshy E. Heat transfer over an exponentially stretching continuous surface with suction. Archives of Mechanics. 2001;53:643-51.

[7] Khan SK, Sanjayanand E. Viscoelastic boundary layer flow and heat transfer over an exponential stretching sheet. International Journal of Heat and Mass Transfer. 2005;48:1534-42.

[8] Partha M, Murthy P, Rajasekhar G. Effect of viscous dissipation on the mixed convection heat transfer from an exponentially stretching surface. Heat and Mass Transfer. 2005;41:360-6.

[9] Mandal IC, Mukhopadhyay S. Heat transfer analysis for fluid flow over an exponentially stretching porous sheet with surface heat flux in porous medium. Ain Shams Engineering Journal. 2013;4:103-10.

[10] Hafidzuddin EH, Nazar R, Arifin NM, Pop I. Numerical solutions of boundary layer flow over an exponentially stretching/shrinking sheet with generalized slip velocity. a a. 2015;2:2.

[11] Mabood F, Khan W, Ismail AM. MHD flow over exponential radiating stretching sheet using homotopy analysis method. Journal of King Saud UniversityEngineering Sciences. 2017;29:68-74. 
[12] Choi SU, Eastman JA. Enhancing thermal conductivity of fluids with nanoparticles. Argonne National Lab., IL (United States); 1995.

[13] Masuda H, Ebata A, Teramae K. Alteration of thermal conductivity and viscosity of liquid by dispersing ultra-fine particles. Dispersion of $\mathrm{Al} 2 \mathrm{O} 3, \mathrm{SiO} 2$ and $\mathrm{TiO} 2$ ultra-fine particles. 1993.

[14] Hamid KA, Azmi W, Mamat R, Usri N, Najafi G. Effect of temperature on heat transfer coefficient of titanium dioxide in ethylene glycol-based nanofluid. Journal of Mechanical Engineering and Sciences (JMES) Volume. 2015;8:136775.

[15] Abdullah A, Mohamad I, Hashim A, Abdullah N, Wei P, Isa M, et al. Thermal conductivity and viscosity of deionised water and ethylene glycol-based nanofluids. JOURNAL OF MECHANICAL ENGINEERING AND SCIENCES. 2016;10:2249-61.

[16] Ehsan MM, Salehin M, Islam A. Investigation of thermal and hydrodynamic behaviour of Al2O3-water nanofluid through a rough parallel plate.

[17] Abidin SZ, Mohamad I, Hashim A, Abdullah N, Hafiz M, Masripan N, et al. Investigation of thermal characteristics of CNF-based nanofluids for electronic cooling applications. JOURNAL OF MECHANICAL ENGINEERING AND SCIENCES. 2016;10:2336-49.

[18] Rahman M. Heat transfer enhancement using hybrid nanoparticles in ethylene glycol through a horizontal heated tube Adnan M. Hussein1, MM Noor2, K. Kadirgama2, D. Ramasamy2 and.

[19] Buongiorno J. Convective transport in nanofluids. Journal of heat transfer. 2006;128:240-50.

[20] Tiwari RK, Das MK. Heat transfer augmentation in a two-sided lid-driven differentially heated square cavity utilizing nanofluids. International Journal of Heat and Mass Transfer. 2007;50:2002-18.

[21] Makinde OD, Aziz A. Boundary layer flow of a nanofluid past a stretching sheet with a convective boundary condition. International Journal of Thermal Sciences. 2011;50:1326-32.

[22] Alsaedi A, Awais M, Hayat T. Effects of heat generation/absorption on stagnation point flow of nanofluid over a surface with convective boundary conditions. Communications in Nonlinear Science and Numerical Simulation. 2012;17:421023.

[23] Mustafa M, Hayat T, Alsaedi A. Unsteady boundary layer flow of nanofluid past an impulsively stretching sheet. Journal of Mechanics. 2013;29:423-32.

[24] Hayat T, Abbasi F, Al-Yami M, Monaquel S. Slip and Joule heating effects in mixed convection peristaltic transport of nanofluid with Soret and Dufour effects. Journal of Molecular liquids. 2014;194:93-9.

[25] Zaimi K, Ishak A, Pop I. Flow past a permeable stretching/shrinking sheet in a nanofluid using two-phase model. Plos one. 2014;9:e111743.

[26] Usri N, Azmi W, Mamat R, Hamid KA. Forced convection heat transfer using water-ethylene glycol (60: 40) based nanofluids in automotive cooling system. International Journal of Automotive and Mechanical Engineering. 2015;11:2747.

[27] Mansur S, Ishak A, Pop I. The magnetohydrodynamic stagnation point flow of a nanofluid over a stretching/shrinking sheet with suction. Plos one. 2015; 10:e0117733. 
[28] Naramgari S, Sulochana C. MHD flow over a permeable stretching/shrinking sheet of a nanofluid with suction/injection. Alexandria Engineering Journal. 2016;55:819-27.

[29] Boyd J, Buick JM, Green S. Analysis of the Casson and Carreau-Yasuda nonNewtonian blood models in steady and oscillatory flows using the lattice Boltzmann method. Physics of Fluids. 2007;19:093103.

[30] Mustafa M, Hayat T, Pop I, Aziz A. Unsteady boundary layer flow of a Casson fluid due to an impulsively started moving flat plate. Heat Transfer-Asian Research. 2011;40:563-76.

[31] Mukhopadhyay S. Effects of thermal radiation on Casson fluid flow and heat transfer over an unsteady stretching surface subjected to suction/blowing. Chinese Physics B. 2013;22:114702.

[32] Nadeem S, Mehmood R, Akbar NS. Optimized analytical solution for oblique flow of a Casson-nano fluid with convective boundary conditions. International Journal of Thermal Sciences. 2014;78:90-100.

[33] Haq R, Nadeem S, Khan Z, Okedayo T. Convective heat transfer and MHD effects on Casson nanofluid flow over a shrinking sheet. Open Physics. 2014;12:862-71.

[34] Mustafa M, Khan JA. Model for flow of Casson nanofluid past a non-linearly stretching sheet considering magnetic field effects. AIP Advances. 2015;5:077148.

[35] Umavathi J, Mohite MB. Convective transport in a porous medium layer saturated with a Maxwell nanofluid. Journal of King Saud University-Engineering Sciences. 2016;28:56-68.

[36] Oyelakin IS, Mondal S, Sibanda P. Unsteady Casson nanofluid flow over a stretching sheet with thermal radiation, convective and slip boundary conditions. Alexandria Engineering Journal. 2016;55:1025-35.

[37] Sulochana C, Ashwinkumar G, Sandeep N. Similarity solution of 3D Casson nanofluid flow over a stretching sheet with convective boundary conditions. Journal of the Nigerian Mathematical Society. 2016;35:128-41.

[38] Rana S, Mehmood R, Akbar NS. Mixed convective oblique flow of a Casson fluid with partial slip, internal heating and homogeneous-heterogeneous reactions. Journal of Molecular liquids. 2016;222:1010-9.

[39] Zaib A, Bhattacharyya K, Uddin M, Shafie S. Dual solutions of non-Newtonian Casson fluid flow and heat transfer over an exponentially permeable shrinking sheet with viscous dissipation. Modelling and Simulation in Engineering. 2016;2016.

[40] Vajravelu K, Prasad K, Datti P, Raju B. Convective flow, heat and mass transfer of Ostwald-de Waele fluid over a vertical stretching sheet. Journal of King Saud University-Engineering Sciences. 2017;29:57-67.

[41] Turkyilmazoglu M. Multiple solutions of heat and mass transfer of MHD slip flow for the viscoelastic fluid over a stretching sheet. International Journal of Thermal Sciences. 2011;50:2264-76.

[42] Sahoo B, Poncet S. Flow and heat transfer of a third grade fluid past an exponentially stretching sheet with partial slip boundary condition. International Journal of Heat and Mass Transfer. 2011;54:5010-9.

[43] Uddin M, Bég OA, Amin N. Hydromagnetic transport phenomena from a stretching or shrinking nonlinear nanomaterial sheet with Navier slip and convective heating: a model for bio-nano-materials processing. Journal of Magnetism and Magnetic Materials. 2014;368:252-61. 
[44] Hayat T, Imtiaz M, Alsaedi A. Impact of magnetohydrodynamics in bidirectional flow of nanofluid subject to second order slip velocity and homogeneousheterogeneous reactions. Journal of Magnetism and Magnetic Materials. 2015;395:294-302.

[45] Ghosh S, Mukhopadhyay S, Vajravelu K. Dual solutions of slip flow past a nonlinearly shrinking permeable sheet. Alexandria Engineering Journal. 2016;55:1835-40.

[46] Hayat T, Shafiq A, Alsaedi A, Shahzad S. Unsteady MHD flow over exponentially stretching sheet with slip conditions. Applied Mathematics and Mechanics. 2016;37:193-208.

[47] Rauf A, Shehzad S, Hayat T, Meraj M, Alsaedi A. MHD stagnation point flow of micro nanofluid towards a shrinking sheet with convective and zero mass flux conditions. Bulletin of the Polish Academy of Sciences Technical Sciences. 2017;65:155-62.

[48] Ishak A. MHD boundary layer flow due to an exponentially stretching sheet with radiation effect. Sains Malaysiana. 2011;40:391-5.

[49] Mabood F, Ibrahim S, Khan W. Framing the features of Brownian motion and thermophoresis on radiative nanofluid flow past a rotating stretching sheet with magnetohydrodynamics. Results in physics. 2016;6:1015-23.

[50] Bhattacharyya K, Layek G. Magnetohydrodynamic boundary layer flow of nanofluid over an exponentially stretching permeable sheet. Physics research international. 2014;2014.

[51] Hayat T, Aziz A, Muhammad T, Alsaedi A. Three-dimensional flow of nanofluid with heat and mass flux boundary conditions. Chinese Journal of Physics. 2017;55:1495-510. 